\section{PRÁTICAS RESTAURATIVAS E OS CONFLITOS COTIDIANOS}

PRÁCTICAS RESTAURATIVA Y CONFLICTOS COTIDIANOS

\section{RESTORATIVE PRACTICES AND EVERYDAY CONFLICTS}

RESUMO: Este artigo consiste em um ensaio teórico sobre Justiça Restaurativa (JR) e o uso de seus princípios diante de conflitos cotidianos. Partindo do entendimento de que é na relação com o outro que produzimos conflitos, apresentamos brevemente noções de conflito como construção social, o desenvolvimento da JR e práticas restaurativas no Brasil e no mundo e, por fim, tecemos reflexões e indagações sobre os efeitos que a utilização dos princípios restaurativos podem produzir quando transpomos seu uso para nossas relações cotidianas.

Palavras-chave: Justiça Restaurativa; Construcionismo social; Conflitos.

RESUMEN: Este artículo consiste en un ensayo teórico sobre Justicia Restaurativa (JR) y el uso de sus principios frente a los conflictos cotidianos. Partiendo del entendimiento de que es en la relación con el otro donde producimos conflictos, presentamos brevemente nociones de conflicto como la construcción social, el desarrollo de JR y las prácticas restaurativas en Brasil y enel mundo y, finalmente, hacemos reflexiones y preguntas sobre los efectos que el uso de principios restaurativos puede producirse cuando transponemos su uso a nuestras relaciones diarias.

Palabras clave: Justicia restaurativa; Construccionismo social; Conflitos.

ABSTRACT: This paper consists of a theoretical essay on Restorative Justice (RJ) and the use of its principles in the face of everyday conflicts. Starting from the understanding that it is in the relationship with the other that we produce conflicts, we briefly present notions of conflict such as social construction, the development of RJ and restorative practices in Brazil and in the world and, finally, we make reflections and inquiries about the effects that the use of restorative principles can produce when we transpose their use to our daily relationships.

Keywords: Restorative Justice; Social constructionism; Conflicts.

\begin{tabular}{l} 
PRÁCTICAS RESTAURATIVA Y CONFLICTOS COTIDIANOS \\
\hline RESTORATIVE PRACTICES AND EVERYDAY CONFLICTS \\
\hline RESUMO: Este artigo consiste em um ensaio teórico sobre Justiça Restaurativa (JR) e o uso de seus \\
princípios diante de conflitos cotidianos. Partindo do entendimento de que é na relação com o outro \\
que produzimos conflitos, apresentamos brevemente noções de conflito como construção social, \\
o desenvolvimento da JR e práticas restaurativas no Brasil e no mundo e, por fim, tecemos reflexões \\
e indagações sobre os efeitos que a utilização dos princípios restaurativos podem produzir quando \\
transpomos seu uso para nossas relações cotidianas.
\end{tabular}

\section{LETÍCIA TROMBINI VIDOTTO ${ }^{1}$}

\section{CAMILA MARTINS LION ${ }^{1}$}

1 Universidade de São Paulo (FFCLRP-USP), Ribeirão Preto, São Paulo, Brasil

Recebido em: 07/12/2019 Aprovado em: 16/01/2020

\title{
ARTIGO
}




\section{CONFLITO COMO CONSTRUÇÃO SOCIAL}

Você conhece alguma pessoa que não possui pelo menos uma história de conflito para narrar? Provavelmente, não. Alguns vivenciam mais conflitos que outros e, o que pode significar uma situação conflituosa para um indivíduo, pode não ter o mesmo significado para outro, entretanto, constantemente conflitos são produzidos no cotidiano das relações humanas.

Compreendendo que conflito é algo conhecido, mas possui diferentes entendimentos acerca do que é, de seus efeitos e modos de reagir a ele, é importante contextualizarmos sobre qual compreensão de produção de conflito estamos fazendo uso para nortear nosso diálogo neste artigo. Deste modo, o intuito não é apresentar um aprofundamento conceitual sobre o conflito, mas dar visibilidade às noções que nos guiam.

De acordo com Winslade e Monk (2016), as pessoas vivem suas vidas através de histórias e, é a partir dessas histórias que contam para e sobre os outros - e a si mesmas - que as pessoas agem, produzem discursos, tomam decisões, escolhem valores, desenvolvem relacionamentos e constroem comunidades. Essas histórias não são parte unicamente de um repertório pessoal, mas também de apropriações de diferentes narrativas que fazem parte de contextos macro. Sendo assim, compreende-se que as pessoas são seres plurais por possuírem diferentes valores, crenças, opiniões e vivências que vão sendo construídas ao longo de suas trajetórias de vida e também por meio das relações que estabelecem dentro de um contexto econômico, histórico, social e cultural (Burr, 2003).

Nesse sentido, no decorrer da história da humanidade construiu-se uma diversidade de normas e padrões que é compreendida de uma maneira ou outra, a depender das diferentes histórias de que participam pessoas, indivíduos, a humanidade. Por exemplo, jeitos esperados de ser ser mulher, ser homem, viver a sexualidade e os relacionamentos amorosos, entre outros discursos sociais. Desse modo, diferentes normas e padrões foram se construindo como certos ou errados, ações foram reconhecidas como boas ou más, além de opiniões e conhecimentos tidos como verdadeiros ou falsos (Foucault, 1996). Essas compreensões podem ser atualizadas de acordo com as transformações que ocorrem em cada momento histórico, como, por exemplo, a ascensão da era virtual e, consequentemente, a ampliação do acesso ao conhecimento e ao diverso.

Os entendimentos sobre algo em detrimento de outros são privilegiados de acordo com as moralidades e discursos construídos nos grupos familiares, sociais, religiosos, entre outros (McNamee, 2019). Essas diferenças podem se tornar um terreno fértil para a produção de conflitos quando reduzimos as pessoas a uma única definição de identidade e fazemos descrições simplistas do outro, sem deixar espaço para a pluralidade de quem esse outro pode ser, ou para que as histórias sejam contextualizadas e possuam coerência em suas ações. Deste modo, o conflito e as possíveis transformações frente a ele são analisados a partir de uma perspectiva relacional, por compreender-se que ele é produzido na comunicação entre as pessoas. (Gergen, McNamee, \& Barrett, 2001).

Além disso, quando um conflito emerge, aprendemos culturalmente a eleger um culpado ou culpar a nós mesmos, como se para o conflito existir fosse necessário apenas uma pessoa. Porém, sensíveis ao construcionismo social, Gergen et al. (2001) compreendem que, se os conflitos ocorrem no território da comunicação, para que um conflito seja produzido, pelo menos duas pessoas precisam estar em comunicação, seja verbal, corporal ou até mesmo virtual.

Quando nos relacionamos levando em conta as dualidades - e não as pluralidades -, podemos entender o conflito como resultante da relação entre 
"vítimas" e "culpados" e ou como sendo composto por um lado "certo" e um "errado". Nesse sentido, remete-se à ideia de um indivíduo que transgride uma norma ou aquilo que se espera dele e deve responsabilizar-se por isso. Frequentemente, na tentativa de moldar o comportamento de quem "errou", a punição aparece como sendo um caminho possível (McNamee \& Gergen, 1999).

Historicamente, a punição foi ocupando um lugar de destaque como uma ação de manejo do comportamento humano e, desde muito cedo, aprendemos que a punição pode ser útil, com uso frequente em diferentes contextos, seja familiar, educacional, social ou jurídico. Contudo, há tempos é possível perceber que nem sempre o uso da punição cumpre sua "promessa" de transformar o outro, solucionar o conflito e alcançar relações mais justas.

Apesar de frequentemente os conflitos serem apontados como ruins e/ou algo a ser evitado, Lederach (2012) menciona a importância de transformar os efeitos negativos do conflito em oportunidade de construção de modos desejáveis de se relacionar. Então, quando um conflito é produzido, o que podemos fazer para transformá-lo? Gergen, McNamee e Gergen (2015) entendem que "se é pelo diálogo que surgem os conflitos, então o diálogo pode ser nossa melhor opção para tratar de realidades conflitantes" (p. 30).

Visto que o construcionismo social compreende que é na relação com as outras pessoas que construímos o entendimento de quem somos, de quem o outro é e do que estamos produzindo juntos em termos de relacionamentos e sentidos sobre a vida, reconhece-se que é nas negociações pela e na própria linguagem, que novas narrativas sobre o problema podem surgir, construindo-se novos entendimentos sobre os conflitos e, consequentemente, novas ações para transformá-lo. Essa parece ser uma aposta que vai ao encontro dos princípios da Justiça Restaurativa (JR).

Neste artigo, propomos apresentar o entendimento acerca da JR nos dias atuais, sua utilização no Brasil, bem como refletir sobre o uso de seus princípios diante dos conflitos produzidos nos relacionamentos cotidianos.

\section{O QUE É JUSTIÇA RESTAURATIVA?}

Não há uma única definição para o que é Justiça Restaurativa (JR) e nem uma única história sobre seu surgimento. Diferentes autores a compreendem de diversos modos, que vão desde o entendimento de um tipo alternativo de administração de conflitos, até a compreensão de uma mudança paradigmática em relação ao que consideramos como justo em nossa sociedade.

Para Palamolla (2009), a JR possui um conceito aberto e fluido, pois vem se modificando desde os primeiros estudos e experiências e, de acordo com Tonche (2015), as diferentes compreensões são o que movimentam o campo. Para esta pesquisadora, existe certo consenso entre os pesquisadores e entusiastas de que os princípios norteadores da JR foram inspirados pelo modo como povos tradicionais reagiam diante dos conflitos, na tentativa de transformá-los por meio de uma lógica que vai além do entendimento da culpabilização e da punição individual.

A tribo indígena da América do Norte, conhecida como Navajo, por exemplo, quando se deparava com a situação de algum membro transgredir uma norma, ao invés de olhar para a transgressão individual, assumia o entendimento de que essa ação refletia um desequilíbrio no grupo como um todo. Diante disso, todo o grupo ocupava o papel de buscar coletivamente superar o problema, reconectando a pessoa que transgrediu ao grupo e aos seus familiares (Jaccoud, 2005). Princípios semelhantes são encontrados em códigos decretados antes da primeira era cristã,

Nova Perspectiva Sistêmica, v. 29, n. 66, p. 49-59, abril 2020. 
como o Código de Lipt-Ishtar (1875 a.C.) e o Código de Hammurabi (1700 a.C), que prescreviam medidas de restituição para os crimes contra os bens. Podem ser também identificados em povos colonizados da África, da Nova Zelândia, da Austrália, da América do Norte e do Sul e em sociedades pré-estatais da Europa (Jaccoud, 2005).

De acordo com Zehr (2008), a conceitualização da Justiça Restaurativa, como conhecimento formalizado, emergiu no decorrer da década 1970 nos Estados Unidos da América (EUA) e Canadá, tendo como marco inicial o Programa de Reconciliação Vítima-Ofensor (Victim-Offender Reconciliation Program - VORP). No Canadá, em 1974, após dois adolescentes terem se envolvido em atos de vandalismo em mais de 20 propriedades na cidade de Ontário e terem se declarado culpados por tais ações, ao invés de utilizarem dos meios tradicionais de punição, a equipe técnica do âmbito jurídico possibilitou a construção de um acordo entre os jovens e os proprietários atingidos pelo vandalismo, na tentativa de explorar alternativas comunitárias de resolução de conflitos. Já nos EUA, iniciou-se a partir de um projeto na Indiana, em 1977, e seguiu-se evoluindo e ampliando o seu uso em diferentes localidades do país (Zehr, 2008).

Também na década de 1970, na Nova Zelândia, percebeu-se que a juventude Maori, um dos povos nativos daquela região, estava envolvida na criminalidade de forma desproporcional quando comparada à população geral, o que parece ter emergido devido à crise econômica no país que favoreceu o aumento das desigualdades sociais e, consequentemente, da marginalização, principalmente desses povos nativos. Objetivando a transformação desse contexto, em 1989, construiu-se uma nova legislação direcionada à infância e à juventude e a Nova Zelândia se tornou o primeiro país a utilizar a JR de forma mais sistemática, produzida por meio das Conferências Familiares (Family Group Conference - FGC), que consistem em reuniões restaurativas com as famílias e comunidade de apoio das vítimas e ofensores, na tentativa de que todos se responsabilizem pelos feitos cometidos, favorecendo reparações econômicas e materiais (Boonen, 2011; Maxwell, 2005; Maxwell \& Liu, 2007). Esses são os casos mais mencionados na literatura quando se fala do movimento de disseminação da JR, contudo, vale mencionar que outros países como Alemanha, Bélgica, Peru, Argentina e Austrália também possuem históricos da introdução de práticas similares desde a década de 1970 (Boonen, 2011).

Como pode ser notado, a década de 1970 colaborou significativamente para o (re)nascimento da Justiça Restaurativa (Jaccoud, 2005). No entanto, em 1990, o lançamento do livro Trocando as Lentes, de Howard Zehr, considerado um dos pioneiros da JR, intensificou a repercussão. Por meio da metáfora da troca de lentes de uma câmera fotográfica, o autor introduziu o que considera um novo paradigma no âmbito da resolução de conflitos e compreensão de justiça: o paradigma restaurativo. Segundo o autor, cada paradigma é como se fosse uma lente e quando trocamos essas lentes, foca-se em diferentes aspectos. O autor acredita que toda precariedade e fracasso em relação ao crime e à justiça são reflexos do uso apenas da lente do paradigma retributivo, o qual utiliza a punição como principal maneira de responder aos conflitos.

A Justiça Retributiva "analisa o crime como uma violação, exclusivamente, da lei, retirando o conteúdo humano, ou seja, as condições intersubjetivas presentes entre o transgressor, a vítima e a sociedade" (Souza, 2019), e a maneira como o sistema entende que pode cessar o conflito é por meio da retribuição, estabelecida pela lei. Ou seja, o Estado retribui uma punição - um sofrimento - na tentativa de mostrar força e prevenir novos atos ilícitos, identificando um agente e culpabilizando-o de forma simplista, considerando apenas o exato momento em que houve a transgressão (Souza, 2019; Zehr, 2008). Enquanto a Justiça Restaurativa considera

Nova Perspectiva Sistêmica, v. 29, n. 66, p. 49-59, abril 2020. 
que o crime é um dano às relações interpessoais, e não uma afronta ao Estado, propondo "devolvê-lo" às partes envolvidas no ocorrido (Christie, 1997), por meio de um diálogo organizado, que leva em consideração aspectos como, por exemplo, contextuais, culturais, subjetivos e sociais. Durante esse diálogo, os participantes compartilham relatos sobre os danos ocasionados pelo ocorrido e constroem juntos as possibilidades de reparação. (Zehr, 2008).

Uma definição mais formal de JR parece ter sido proposta em 1996, por Tony Marshall, que considerou que "Justiça Restaurativa é um processo pelo qual as partes envolvidas em uma específica ofensa resolvem, coletivamente, como lidar com as consequências da ofensa e as suas implicações para o futuro" (p. 37). Essa definição foi adotada pela ONU na Resolução 12/2002 pelo Conselho Econômico e Social das Nações Unidas e, para Boonen (2011), essa é uma das datas mais marcantes no desenvolvimento da Justiça Restaurativa no cenário jurídico legal internacional, pois a ONU convidou os Estados-membros a iniciar pesquisas de implementações, capacitações e atividades que envolvessem procedimentos restaurativos. Essa definição também reflete o modo pelo qual a JR foi inicialmente difundida no Brasil.

O Ministério da Justiça Brasileiro, a partir do início do século XXI, por intermédio da Secretaria da Reforma do Judiciário, buscou realizar uma reestruturação do acesso à justiça para enfatizar a função participativa do Judiciário na democratização da sociedade e na universalização e garantia dos direitos econômicos, sociais, culturais e ambientais (Melo, Ednir, \&Yazbek, 2008). A partir desse contexto foi elaborado, em 2005, o projeto "Promovendo Práticas Restaurativas no Sistema de Justiça Brasileiro", e três projetos-piloto nacionais foram implantados com financiamento da Secretaria de Reforma do Judiciário e do Programa das Nações Unidas para o Desenvolvimento, nas cidades de São Caetano do Sul, SP, em Porto Alegre, RS e em Brasília, DF (Melo, Ednir, Yazbek, 2008). Esses três projetos focaram em públicos e estratégias diferentes de aplicação da JR, de modo a compreender os desafios e possibilidades em contextos diversos.

No intuito de regulamentar a Política Nacional de Justiça Restaurativa no contexto do Poder Judiciário, em 2016, o Conselho Nacional de Justiça (CNJ) instaurou a Resolução 225, dispondo sobre a Política Nacional de Justiça Restaurativa no âmbito do Poder Judiciário e de outras providências, enfatizando que o conflito e a violência são fenômenos complexos e, portanto, há necessidade de favorecer uma transformação paradigmática que contemple os aspectos individuais, relacionais, comunitários, institucionais, econômicos e sociais. Segundo esta resolução, a JR se concebe como

um conjunto de princípios, métodos, técnicas e atividades próprias visando à conscientização sobre os fatos relacionais, institucionais e sociais motivadores de conflitos e violência, e por meio do qual os conflitos que geram dano, concreto ou abstrato, são solucionados de modo estruturado. (p. 3)

Além disso, a Resolução n. 225 (2016) descreve os princípios norteadores da JR, tendo entre eles a reparação dos danos, o atendimento às necessidades de todos os envolvidos, a voluntariedade, a confidencialidade e a imparcialidade. Para que tais princípios possam ser contemplados, a resolução discorre também sobre a organização dos procedimentos restaurativos e aponta as atribuições do CNJ e dos Tribunais de Justiça, que sustentadas por uma variedade de linhas programáticas, definem os aspectos relacionados ao atendimento restaurativo dentro do contexto judicial e as funções dos facilitadores neste âmbito, visando ao favorecimento de atos de estímulo, acompanhamento e avaliação do andamento da JR (Resolução n. 225, 2016). 
1 Os processos circulares têm sido amplamente disseminados no Brasil pela autora canadense Kay Pranis, que já esteve no país ministrando diversos cursos e palestras nos últimos anos. Para além da utilização em situações com conflitos instaurados, esses círculos são utilizados em instituições, equipes e escolas, de modo a favorecer a emergência de um senso comunitário e construção de paz, por meio do compartilhamento de sentimentos, necessidades, escuta qualificada e empoderamento de todos os participantes (Pranis, 2010).
Além dessa, a Resolução 288, de 2019, define a política institucional do Poder Judiciário para a promoção da aplicação de alternativas penais, com enfoque restaurativo, em substituição à privação de liberdade, estimulando medidas de intervenção em conflitos e violências diferentes do encarceramento, orientadas para a restauração das relações a partir da responsabilização com dignidade, autonomia e liberdade, que podem ser aplicadas por meio de conciliação, mediação e técnicas de Justiça Restaurativa (CNJ, 2019).

Apesar dessas resoluções, para muitos disseminadores, a JR não pretende substituir a Justiça Retributiva. Para Barter (comunicação pessoal, 2019), a JR entra na "justiça formal" como um novo mecanismo, não como solução para as irritações dos mecanismos atuais, ou seja, não sugere a troca de uma pela outra, mas a complementação, já que, em seu ponto de vista, a retribuição não tem funcionado integralmente. Além disso, é importante ressaltar que, durante um processo restaurativo, não necessariamente se chega à reparação do dano resultante de um conflito, apesar de, em alguns casos, se alcançar esse resultado.

Embora 2005 ser amplamente reconhecido como o ano em que a JR começou a ser difundida no Brasil, iniciativas anteriores já estavam ocorrendo no país. Dominic Barter, facilitador reconhecido pelo desenvolvimento e formação em Comunicação Não Violenta $(\mathrm{CNV})$ no país, relata realizar práticas que podem ser nomeadas como JR em meados dos anos 90, em comunidades do Rio de Janeiro (D. Barter, comunicação pessoal, 2019). É importante destacarmos isso pois, ainda que tenha existido a tentativa de aplicação da JR em escolas desde os projetos-pilotos de 2005, com a expansão da JR no Brasil cada vez mais incentivada pelo sistema judiciário brasileiro, colaborou-se para a compreensão de JR como algo vinculado apenas ao sistema judiciário.

No entanto, diversos autores sugerem a aplicação da JR em outros contextos para além do sistema judiciário (Hopkins, 2004; Morrison, 2005; Pranis, 2010), sendo que alguns preferem nomear essas aplicações de "práticas restaurativas".

Além da complexidade da definição, mesmo esses autores que sugerem a JR em maior amplitude parecem considerar essa possibilidade em diferentes perspectivas. Alguns sugerem que podemos aplicá-la em escolas, empresas e comunidades, transformando conflitos sem que exista a necessidade de que eles se transponham para o sistema, ampliando-se, deste modo, o acesso ao justo, antes vinculado apenas ao âmbito jurídico. Aqui, para re-estabelecer o justo e/ou as relações, levase em conta a mudança de paradigmas e responde-se ao conflito por meio de um processo restaurativo.

Outros autores sugerem que a JR - ou práticas restaurativas - pode ir ainda mais além e que, ao considerar o paradigma restaurativo, que leva em conta princípios como horizontalidade, respeito e voluntariedade, é possível aplicá-la em todos os contextos do cotidiano, mesmo sem haver a necessidade de pessoas em conflito, como são as iniciativas dos Círculos de Construção de Paz ou os Círculos de Convivência ${ }^{1}$. Essas parecem utilizar ferramentas e princípios da JR, mas ao invés do foco na transformação de um conflito, possibilitam a conexão e diálogos entre grupos de modo a prevenir a instauração dele, colaborando para a construção de relações mais justas e de um novo entendimento de justiça.

Para caminhar em direção a esses diferentes objetivos, diversos formatos são possíveis, o que também colabora para a diversidade de entendimentos sobre JR. Além dos Círculos Restaurativos, que já abarcam tipos diferentes, a Mediação Vítima-Ofensor e as Conferências Familiares são, dentre outros, formatos possíveis.

Quando apresentamos esses formatos e a diferenciação de compreensões sobre eles, não estamos sugerindo que seja necessário optar por apenas uma deles ou de 
que um seja mais Justiça Restaurativa do que outra. Nosso intuito é gerar a reflexões acerca dos efeitos quando aplicamos essas práticas com cada foco, ou, ainda, em complementariedade.

Desde sua maior expansão, em 2005, uma série de iniciativas de uso da JR e/ou práticas restaurativas se desenvolveu simultaneamente nos estados brasileiros e pode ser encontrade em diferentes projetos de juizados, políticas públicas, escolas e comunidades do país. Além disso, diversos fóruns, reuniões e cursos de capacitação para facilitadores de JR são realizadas, onde trocam-se experiências, possibilidades e desafios de sua aplicação. Saindo da tensão da definição, nosso objetivo é aproveitar as reflexões acerca do tema e a expansão desse modelo de justiça no Brasil, para incentivar a ampliação dos princípios da JR para outros contextos além do sistema judiciário, de modo que, cada vez mais, as pessoas conheçam outras possibilidades de manejo de conflitos e, mesmo que aos poucos, possamos fomentar o compartilhamento de relações mais baseadas em restauração do que em retribuição.

\section{PRÁTICAS RESTAURATIVAS E OS CONFLITOS COTIDIANOS}

Além de diversas pesquisas em outros países já demonstrarem os benefícios das práticas restaurativas em diferentes âmbitos (Crisostomo, 2008; Kennedy, Tuliao, Flower, Tibbs, \& McChargue, 2019), no Brasil, é possível verificar os resultados de aplicação em alguns projetos, como é o exemplo da cidade de Santos, no litoral paulista, que teve uma queda de $97,35 \%$ no número de casos de agressão, bullying, vandalismo e outros conflitos registrados dentro das escolas municipais entre 2014 e 2019 (Prefeitura de Santos, 2019).

Mas o que, afinal, ocorrem nessas conversas que as tornam úteis? Ao compreender como o construcionismo social entende as pessoas e as relações, aposta-se nas re-negociações pela própria linguagem de modo colaborativo e horizontal (Gergen et al., 2001) o que vai ao encontro da prática proposta pela JR. Gergen (2009) compreende que a JR é um dos processos dialógicos existentes que favorece um diálogo transformador por não focar nas disputas de conteúdos que englobam os conflitos. Deste modo, o foco está na ação coordenada entre as pessoas, isto é, no que as pessoas estão fazendo juntas e o que podem produzir de novo acerca da situação vivida.

Ao colocar as pessoas envolvidas em um conflito em diálogo, possibilita-se que, por meio da contação de histórias, negociem-se novos entendimentos sobre o conflito. Em outras palavras, é através do compartilhamento de histórias pessoais, que se possibilita a contextualização de suas vidas, suas dificuldades, necessidades, sentimentos e compreensões sobre o conflito ocorrido. Esse compartilhamento é uma oportunidade de as pessoas compreenderem os sentidos produzidos nas histórias umas das outras e, mesmo discordando, pode ser uma oportunidade de conhecer o que ocorre no contexto e história pessoal de uns e outros que contribuiu para que aquele conflito tenha acontecido. Ou seja, esse compartilhamento permite a ampliação de entendimentos e muitas vezes a produção de convergências, possibilitando que as pessoas se conectem com aspectos de suas vidas.

Nesse sentido, se a JR vem sendo disseminada e se mostrando útil para transformação de conflitos que envolvam danos e/ou violência, será que podemos utilizar seus princípios como recurso no nosso dia a dia, de modo diferente dos recursos punitivos, dos quais muitos de nós nos acostumamos? Como transpor a JR para as práticas cotidianas? O que muda quando nos relacionamos recorrendo aos princípios da JR?

Nova Perspectiva Sistêmica, v. 29, n. 66, p. 49-59, abril 2020. 
Por nossa cultura valorizar e nos educar considerando um modelo de Justiça focado em culpa e punição, agimos e reagimos aos nossos relacionamentos levando em conta os princípios dessa ótica. Nas escolas, quando uma criança ou adolescente age de modo diferente do que esperamos, as punimos por meio de diferentes ações: afastamos a criança de onde houve o conflito, aplicamos castigos, retiramos algo de valor para ela, utilizamos exemplos de punição para ameaçá-la de modo a prevenir outros conflitos, sendo que, em muitos casos, a punimos sem mesmo possibilitá-la uma compreensão dos motivos daquela ação ser diferente do esperado por nós.

O mesmo pode ser visto nas empresas e em outras relações cotidianas. Quando um funcionário faz algo não permitido, não aceito ou considerado errado perante aquela comunidade, ele é punido. Aplicam-se advertências, demissões por justa causa, afastamentos e trocas de funções para separar as pessoas envolvidas em conflito. Em nossas famílias, punimos nossos filhos quando algo sai do esperado do que valorizamos. Nós os castigamos, isolamos e repreendemos pelos erros cometidos. Quando participamos de algum conflito familiar ou em relações de amizade, buscamos procurar um culpado, um certo e errado, e reagimos, seja por meio do embate ou do afastamento.

Ao utilizarmos essas explicações dualistas, consequentemente, produzimos reações punitivas. Mas como seria se, ao nos depararmos com uma situação conflituosa em nossa rotina, pudéssemos refletir e considerar o contexto do qual as outras pessoas fazem parte, ouvíssemos suas histórias, suas motivações e necessidades para agirem de maneira diferente de como consideramos adequada?

Como seria se, ao invés de sempre debater e/ou nos afastar de pessoas que demonstram opiniões diferentes das nossas, tentássemos compreender quais as necessidades que essas pessoas possuem que as fazem agir ou pensar de determinada maneira? Quais resultados encontraríamos se, ao nos deparar com um conflito entre funcionários de nossa empresa, ao invés de ouvir os envolvidos separadamente e decidir por uma parte certa ou errada, possibilitássemos uma conversa entre todos, de modo que esses possam se ouvir e pensar como podem continuar juntos? Ou se, ao invés de expulsar um aluno por comportamento inadequado, levássemos em conta sua história familiar e pudéssemos expor como suas ações afetam os outros e que, para que possam continuar convivendo, precisam pensar em ações coletivas?

Ao transpormos a JR para as práticas cotidianas, não estamos sugerindo que seja necessário sistematizar conversas complexas sob a luz de alguma metodologia de JR toda vez que um conflito ocorrer. Dependendo da complexidade do conflito, não será necessário convidar e preparar as pessoas envolvidas para um encontro entre elas. Em muitos momentos, podemos contribuir como facilitadores em nossa rotina, realizando perguntas de reflexão que possibilitam um ampliamento do entendimento do conflito à luz dos princípios da JR para um amigo ou familiar que nos relata uma questão, ou realizando essas perguntas a nós mesmos.

O que produzimos quando nos relacionamos sob a ótica retributiva? Quais os efeitos de buscarmos justiça, reparação e/ou mudanças em nossas relações por meio de ações punitivas? E quais os efeitos de buscarmos o justo por meio de ações restaurativas? Essas perguntas não possuem respostas certas ou únicas. Elas abrem espaço para que apareçam outros aspectos relacionados aos conflitos e, quem sabe, produzam novos entendimentos em relação a isso.

Nosso convite, portanto, é de olhar também para os conflitos cotidianos e transformar o modo como reagimos a eles, optando por ações mais restaurativas e menos retributivas. Ao exercitar esses posicionamentos no dia a dia, colaboramos para uma transformação cultural em relação à punição e aos conflitos, favorecendo as possibilidades que o paradigma restaurativo nos abre, causando menos estranheza e, ampliando seu uso, inclusive, em ações no sistema penal.

Nova Perspectiva Sistêmica, v. 29, n. 66, p. 49-59, abril 2020. 
O lema do Taos Institute, instituto que aposta em práticas dialógicas, é de que podemos transformar o mundo realizando uma conversa de cada vez. Sabemos que exercitar esses diálogos e levar em consideração outro paradigma não é tarefa fácil. Partindo da compreensão de que o compartilhamento de histórias colabora para a ampliação de entendimentos e, de que o objetivo deste artigo é gerar reflexões e transformações práticas, destacamos a sequência de perguntas utilizadas por O’Connell (2008), australiano pioneiro no desenvolvimento dessas práticas, que podem inspirar o exercício das práticas restaurativas diante de situações conflituosas:

"O que aconteceu?"

"O que vocêestava pensando naquele momento? O que você pensou desde então?"

"Como isso impactou você e outras pessoas? De que maneira?

"Qual foi a coisa mais difícil sobre o que aconteceu?"

"O que você acha que precisa acontecer para corrigir as coisas?"

Apostando no entendimento de que perguntas podem abrir mais caminhos de reflexões do que frases de certezas absolutas, encerramos este artigo com o desejo de que esses diálogos continuem.

\section{REFERÊNCIAS}

Burr, V. (2003). Social Constructionism. London: Routledge.

Boonen, P. (2011). A Justiça Restaurativa, um desafio para a educação. Tese de Doutorado, Programa de Pós-graduação em Educação, Universidade de São Paulo, SP. Recuperado de www.teses.usp.br.

Christie, N. (1997). Conflict as Property. British Journal of Criminology, 17(1), 1-15. Recuperado de https://doi.org/10.1093/oxfordjournals.bjc.a046783.

Crisostomo, R. (2008). The Effectiveness of Restorative Justice Practices: How to Restore Justice for At-Risk. Dissertação de Mestrado, Programa de Pós-graduação em Educação, School of Education Dominican, University of California, CA.

Resolução n. 225, de 31 de maio de 2016. (2016). Dispõe sobre a Política Nacional de Justiça Restaurativa no âmbito do Poder Judiciário e dá outras providências. Recuperado de http://www.cnj.jus.br/atos-normativos?documento=2289.

Conselho Nacional de Justiça (2019). Resolução No 288 de 25/06/2019. Define a política institucional do Poder Judiciário para a promoção da aplicação de alternativas penais, com enfoque restaurativo, em substituição à privação de liberdade. Recuperado de https://atos.cnj.jus.br/atos/detalhar/ atos-normativos? documento $=2957$.

Foucault, M. (1996). A ordem do discurso. São Paulo: Editora Loyola.

Gergen, K. L. (2009). Relational being beyond self and community. New York: Oxford University Press.

Gergen, K. J. \& Gergen, M. (2010). Construcionismo social: um convite ao diálogo. Rio de Janeiro: InstitutoNoos.

Gergen, K. J., McNamee, S., \& Barrett, F. J. (2001). Toward Transformative Dialogue. International Journal of Public Administration, 24(7-8), 679-707.

Hopkins, B. (2004). Just Schools - A Whole School Approach to Restaurative Justice. United Kingdom: KingsleyPublishers. 
Jaccoud, M. (2005). Princípios, tendências e procedimentos que cercam a Justiça Restaurativa. In C. Slakmon, R. De Vitto, \& R. S. G. Pinto (Orgs.), Justiça Restaurativa (pp. 163-188). Brasília, DF: Ministério da Justiça e Programa das Nações Unidas para o Desenvolvimento - PNUD. Recuperado de http://carceraria.org.br/wp-content/uploads/2014/07/Coletanea-de-ArtigosLivro-Justi\%C3\%A7a-Restaurativa.pdf

Kennedy, J. L. D., Tuliao, A. P., Flower, K. L. N., Tibbs, J. J., \& Mcchargue, D. E. (2019). Long-Term Effectiveness of a Brief Restorative Justice Intervention. International Journal of Offender Therapy and Comparative Criminology, 63(1), 3-17. https://doi.org/10.1177/0306624X18779202

Lederach, J. P. (2012). Transformação de conflitos. Série da reflexão à ação. São Paulo: Palas Athena.

Marshall, T. (1996). The evolution of restorative justice in Britain. European Journal on Criminal Policy Research, 4(4), 21-46, Heidelberg: Springer.

Maxwell, G. (2005). A Justiça Restaurativa na Nova Zelândia. In C. Slakmon, R. De Vitto, \& R. S. G. Pinto (Orgs.), Justiça Restaurativa (pp. 281-298). Brasília, DF: Ministério da Justiça e Programa das Nações Unidas para o Desenvolvimento - PNUD. Recuperado de http://carceraria.org.br/wp-content/uploads/2014/07/ Coletanea-de-Artigos-Livro-Justi\%C3\%A7a-Restaurativa.pdf

Maxwell, G. \& Liu, J. H. (2007). Restorative Justice and Practices in New Zealand: towards a Restorative Society, 37(3), 60-64. Nova Zelândia: Institute of Policy Studies. Recuperado de http://www.psychology.org.nz/wp-content/uploads/ NZJP-Vol373-2008-9-Book-Ward.pdf

McNamee, S. (2019). Diálogo Transformador: coordenando moralidades conflitantes. In M. Grandesso (Org),Construcionismo social e práticas colaborativo-dialógicas: contextos de ações transformadoras (pp. 57-70). Curitiba: CRV.

McNamee, S. \& Gergen, K. J. (1999). Relational Responsibility, Resources for sustainable dialogue. London: Sage Publication. International Handbooks.

Melo, E. R., Ednir, M., \& Yazbek, V. C. (2008). Justiça Restaurativa e Comunitária em São Caetano do Sul: aprendendo com os conflitos a respeitar direitos e promover cidadania. São Paulo: CECIP.

Morrison, B. (2005). Justiça Restaurativa nas Escolas. In C. Slakmon, R. De Vitto, \& R. S. Pinto (Orgs.), Justiça Restaurativa: coletânea de artigos (pp. 439-458). Brasília, DF: Ministério da Justiça e Programa das Nações Unidas para o Desenvolvimento - PNUD.

Palamolla, R. P. (2009). Justiça Restaurativa: da teoria à prática. São Paulo: IBCCRIM. Pranis, K. (2010). Processos Circulares. São Paulo: Palas Athena.

Prefeitura de Santos. (2019). Saiba como Santos conseguiu reduzir em quase $100 \%$ os casos de bullying nas escolas. Recuperado de https://www.santos.sp.gov. br/?q=noticia/saiba-como-santos-conseguiu-reduzir-em-quase-100-os-casosde-bullying-nas-escolas

Souza, C. E. A. (2019). A justiça restaurativa como alternativa à justiça retributiva. Recuperado de https://jus.com.br/ artigos/73735/a-justica-restaurativa-como-alternativa-a-justica-retributiva

Tonche, J. (2015). A construção de um modelo "alternativo" de gestão de conflitos: usos e representações de justiça restaurativa no estado de São Paulo. Tese de Doutorado, Programa de Pós-graduação em Filosofia, Letras e Ciências Humanas, Universidade de São Paulo, São Paulo. Recuperado de http://teses.usp.br.

Nova Perspectiva Sistêmica, v. 29, n. 66, p. 49-59, abril 2020. 
0'Connell,, T. (2008). Restorative Justice Pioneer Terry O'Connell Awarded Honorary Doctorate. Recuperado de https://www.iirp.edu/news/ restorative-justice-pioneer-terry-o-connell-awarded-honorary-doctorate.

Winslade, J., \& Monk, G. (2016). Mediação narrativa: uma abordagem diferenciada para resolução de conflitos. Nova Perspectiva Sistêmica, 54, 7-16, Rio de Janeiro: NOOS.

Zehr, H. (2008). Trocando as Lentes: um novo foco sobre o crime e a justiça. São Paulo: Palas Athena.

\section{LETÍCIA TROMBINI VIDOTTO}

Psicóloga pela Universidade Federal do Triângulo Mineiro (UFTM). Mestra e doutoranda pelo Programa de Pós-Graduação em Psicologia da Faculdade de Filosofia, Ciências e Letras de Ribeirão Preto da Universidade de São Paulo (FFCLRP-USP), com período sanduíche na University of New Hampshire, nos EUA. Membro do grupo de pesquisa do CNPq, DIALOG: Laboratório de Pesquisa em Práticas Dialógicas e Colaborativas. Conciliadora e mediadora de Conflitos com ênfase em Mediação de Equipes pelo Instituto ConversAções. Formação em Mediação Penal pela AJURIS; Fundamentos da Justiça Restaurativa pelo CDHEP; The Power of Dialogue, pelo Essential Partners em Boston (EUA). Facilitadora de círculos restaurativos pela EPM e facilitadora de círculos para Justiça Restaurativa, pelo Instituto ConversAções.

https://orcid.org/0000-0002-1367-3074

E-mail: leticiatvidotto@gmail.com

\section{CAMILA MARTINS LION}

Psicóloga pelo Centro Universitário Unifafibe (2011). Especialista em Intervenção Familiar Sistêmica pela Faculdade de Medicina de São José do Rio Preto - FAMERP (2013). Certificada Internacionalmente em Práticas Colaborativas e Dialógicas pelo Houston Galveston Institute and The TAOS Institute e Interfaci. Membro do grupo de pesquisa do CNPq, DIALOG: Laboratório de Pesquisa em Práticas Dialógicas e Colaborativas. Doutoranda em Psicologia pela FFCLRP-USP (Bolsista CAPES). Experiência na área de psicologia clínica, social e facilitação de grupos.

https://orcid.org/0000-0001-6096-6024

E-mail: camila.m.lion@hotmail.com

Nova Perspectiva Sistêmica, v. 29, n. 66, p. 49-59, abril 2020. 